\title{
Masculinity in Ambiguity: Constructing Taiwanese Masculine Identities Between Great Powers
}

\author{
Ying-Chao Kao and Herng-Dar Bih
}

Masculinities are sets of gender practices that are constructed and embedded in certain historical, cultural, and social contexts (Connell 1987, 1995, 2002a, b, 2005). While previous studies have emphasized the multiplicity and complications of national masculinities, some regional masculinities which have emerged from diplomatically marginalized areas may have been ghettoized or even ignored. At the international level, understanding of masculinities is dominated by the perspective of Euro-American men, marginalizing the voices of masculine selves in Taiwan (i.e., Republic of China, ROC). As an island state widely seen as a "political orphan," Taiwan is also ignored in the context of regional masculinity studies (Taga 2005).

In contrast to masculinities in many other countries, masculine subjects in Taiwan have developed in the context of a conflicting politico-economic structure. Taiwan has a strong global economic presence but is politically isolated. Since 1895, Taiwan endured 50 years of Japanese colonialism, followed by 38 years of authoritarianism under the KMT regime, but then emerged as a model of democratization and industrialization over the past two decades. The gap between Taiwan's economic strength and political influence has led to the development of masculinity in ambiguity in Taiwanese men.

This ambiguity is derived from international politics but is manifested in the interpersonal and intrapsychic levels of Taiwanese masculine selves (Simon and Gagnon 1987, 2003). In the past cold-war framework, Taiwan was viewed as a buffer between the democratic, US-led world and the communist world (led by Russia and China). This buffer created an ambiguous gray zone for great powers to negotiate their political and economic interests, while forcing Taiwanese men into a

\footnotetext{
Y.-C. Kao $(\bowtie)$

Department of Sociology, Rutgers University, 26 Nichol Ave, New Brunswick, NJ 08901, USA

e-mail: ykao@sociology.rutgers.edu

H.-D. Bih

Graduate Institute of Building and Planning, National Taiwan University,

1, Sec. 4, Roosevelt Road, Taipei 106, Taiwan

e-mail: hdbih@ntu.edu.tw
} 
submissive position. This ambiguity has caused Taiwanese men to pragmatically self-identify as secondary global citizens, who are allowed to develop economic strength, but prevented from fully defending their diplomatic interests with other full-fledged nations. This has had a significant impact on the efforts of Taiwanese to position themselves strategically among three great regional powers (i.e., the United States, China, and Japan) and survive within such a structure.

These structural tensions and conflicts have created a socially bipolar environment in which Taiwanese men seek to develop their masculine selves in the mental world. They are accustomed to switching roles between powerful and powerless and to reconcile their ambivalent positions between being masculinized and feminized. They often have to calculate when to yield their dignity and when to defend the principles.

At the individual level, throughout the course of their lives, Taiwanese men face a series of tensions and conflicts extended from the larger society, especially in their adolescence, early adulthood, and mid-adulthood. The school life of Taiwanese male adolescents is dominated by an education system which emphasizes economic upward mobility. Thus, most male students follow the prescribed social norms but are reluctant to be viewed as teacher's pets. After the age of 18, Taiwanese men are subject to mandatory military service. However, the ROC's nominal military rival - the People's Republic of China - has morphed from an adversary to one of Taiwan's most significant trading partners, thus obviating the original purpose of their conscription. In early adulthood, Taiwanese men undergo military socialization which prepares them for employment in mid-adulthood. After stepping into the job market, many Taiwanese men are confronted with business situations which expose them to aspects of the sexual entertainment industry. Participation in sexual activities (implicit or explicit) while engaged in business with colleagues and clients is regarded as an act of male solidarity useful for facilitating business deals or resolving workplace conflicts but incurs a cost in terms of money, time away from family, and marital stability.

This chapter examines mental tension and conflicts at both the macro and micro levels of Taiwanese men to identify ambiguities in Taiwanese conceptualization of masculinity. On the one hand, this research gives voice to those who have been silenced in East Asian studies of men and masculinities in the English-speaking world and thus expands and complements our understanding of the diversity of global masculinities. On the other hand, it draws attention to the development and transformation of this ambiguous Taiwanese masculinity. The construction of masculinities in Taiwan is discussed in the context of three popular and important gender practices which are fairly unique to Taiwan: aluba, doing soldier, and flower drinking, which are respectively associated with the adolescence, early adulthood, and mid-adulthood of Taiwanese men. We begin with a discussion of the similarity and inconsistency between Taiwanese and other East Asian masculinities, followed by a critical reading of wen-wu masculinity (Louie 2003) as an analytic tool for Taiwanese/Chinese masculinities. We then present three examples of the above-mentioned gender practices as a sequence and emphasize their significance by comparing them with the Western pattern raised by Mac an Ghaill (1994). Finally, based on the Taiwanese case, we provide a new framework of ambiguous masculinity. We call for a more global framework of studies into sociopsychological masculinity, taking into consideration 
international politics and the global economy, challenging presumed national categories, and articulating macro and micro levels of masculinities, while illuminating how men's masculine identities evolve and are self-constructed over their lives. However, before attempting to understand the ambiguity of Taiwanese masculinity, we must first explain the current lack of understanding in this research area.

\section{Understanding Taiwanese Masculinity in Transition}

The significance and fruitfulness of studies of Taiwanese masculinities have been underrepresented in the English-speaking world. In the anthology of global masculinities studies, Handbook of Studies on Men and Masculinities (Kimmel et al. 2005), Japanese scholar Futoshi Taga (2005) provides a comprehensive picture of East Asian masculinities in the traditional, modern, post-World War II, and contemporary eras. Taga accurately criticizes studies on East Asian masculinities as being "small in quantity and ... relatively unknown" (p. 129) in the English-speaking world in which our knowledge of masculinities is dominated by Western perspectives or Western-produced research. But while he assumes that nationality is the primary form of categorization for East Asian masculinity, he largely ignores Taiwan which is an economic entity with an ambiguous political status which features independent social institutions and shares aspects of regional culture. The exclusion of Taiwan reflects an inability to challenge assumptions regarding national boundaries to include more diverse masculinities, as well as a failure to assess how Taiwan's political ambiguity substantially and metaphorically extends to the social and mental worlds of men.

Underrepresentation of Taiwanese masculinity may also result from the unquestioned reduction of Chinese masculinity. Indeed, Taiwan has inherited a predominately traditional Chinese culture and gender regime due to long-term governance by the Qing dynasty (1683-1895) and the Kuomintang (KMT, 1945-2000) prior to the first transfer of political power in 2000. However, its history of colonization under Spain and the Netherlands (1624-1662) and later under Japan (1895-1945) and the divergent politico-economic development following 1949 have led to the development of an immigrant society in Taiwan with a hybrid gender culture, resulting in Taiwan's development of social and cultural conditions unique from those in contemporary China and other East Asian countries.

The masculinities in Taiwan and other areas of East Asia have similarities and differences in both intellectual and historical contexts. From the intellectual perspective, compared with other East Asian masculinities, Taiwanese men are forced to face what we call double castration anxiety. On the one hand, Taiwanese men share the burden of stereotypes which Western society imposes upon Asian (American) men, seeing them as "inscrutable" and "more conservative," "less sexual," and "more intelligent" (Doyle 1989, pp. 290-291; see also in Louie 2003, p. 2). Confirming Edward Said's (1978) criticism toward orientalism, Louie (2003) argues that Asian men are racially castrated, while their masculinity is "penetrated, silenced, and possessed" (p. 3). 
On the other hand, unlike men from other East Asian countries, Taiwanese men are also nationally castrated. In everyday life, they are forced to continuously defend and fight for their masculinity based on national identity. When traveling abroad, Taiwanese men are frequently mistaken as being from the PRC, forced to provide additional explanation or documents to clear in dealing with immigration or law enforcement personnel to clarify their national status.

In matters of international diplomacy, due to the PRC's suppression of Taiwan's international status, Taiwanese men are forced to assume unofficial identities (under corporations, NGOs, or academic institutions) to attend events sponsored by international organizations such as the United Nations or World Bank. ${ }^{1}$ Even as Taiwanese athletes win Olympic medals, the ROC national anthem and flag are banned from the venues. Instead, they compete under the collectivity of "Chinese Taipei," regardless of whether they actually live in Taipei or not.

Double castrations due to racial desexualization and lack of national recognition put Taiwanese men in a doubly submissive position in international hierarchies of masculinity. In the competition with other globally hegemonic masculinities, for example, Caucasian or Black masculinity, Taiwanese men feel "psychologically 'besieged' and thus not quite 'normal"' (Zhong 2000; see also in Louie 2007, pp. 63-65) but also sociopsychologically isolated and invisible. At a minimum, while other East Asian men possess national identities upon which to build masculinities, Taiwanese men's nationality and gender-two of fundamental categories to develop individual and collective identities - remain questioned and unstable and become the core sources of ambiguous masculinity.

Acknowledging this failure to illuminate this issue of national castration anxiety leads us to consider the limited current understanding of Chinese masculinity, which is substantially related to Taiwanese masculinity. Louie $(2002,2007)$ correctly rejects viewing the "yin-yang dyad" as an explanatory and descriptive tool for Chinese masculinity due to its mistaken emphasis on a two-sex dichotomy. Rather, he argues that the "wen-wu paradigm" is a better framework to capture both of the mental or civil ideal (wen) and the physical or martial ideal $(w u)$ in Chinese masculinity.

Following Louie, we consider the wen-wu paradigm as a better framework for Taiwanese masculinity than the yin-yang dyad for four reasons. The yinyang dyad has largely dominated Western understanding on Chinese masculinity but covertly perpetuates the dichotomy of gender and leads to tautological fallacies. ${ }^{2}$ Second, the wen-wu paradigm creates a new framework to analyze different combinations of two ideal types. This allows a Taiwanese man to be simultaneously wen (intellectually outstanding) and $w u$ (physically strong), as opposed to yin (feminine) or yang (masculine). Thus, the wen-wu framework fundamentally breaks up the Western mind-body dualism and appeals to be a more holistic perspective on manhood, not only balancing wen and $w u$ ideals but also ultimately invoking multiple masculinities with different combinations of wen and $w u$ performance.

Third, like Chinese masculinity, for Taiwanese masculinity, the wen-wu paradigm shows the exclusion of women from male-dominated realms. Take terms for military 
leaders, for example: Both the titles of civil generals (wen-jiang) and martial generals (wu-jiang) are reserved for males, while female officers are symbolically identified as women's headdress, compared with male's bear (jinguo-burang-xumei).

Thus, the wen-wu paradigm presents a new approach for theorizing and locating Taiwanese masculinity in the context of global hierarchies of masculinity. It rejects the hegemony of Euro-American masculinity and reveals stereotypes and misunderstandings that the West imposes upon Taiwanese masculinity. Furthermore, the wen-wu philosophy provides a possible schema by which to integrate both mental/ physical and intellectual/martial ideals, thus allowing for the construction of a more comprehensive framework for understanding masculinity in Taiwanese and Chinese contexts as opposed to the Western dualist system.

However, previous Chinese studies are mainly derived from textual analysis (especially ancient and historical texts) rather than fieldwork or ethnography that would give voice to living men. In addition, most of these studies seek generalizable versions of Chinese masculinity across macro history, disregarding micro history which sheds light on how masculinities have developed throughout life-span stages.

To fill the gaps, this research provides a Taiwan-centered investigation of how masculinities have been shaped in specific historical and social contexts and how Taiwanese men develop masculine selves across their life spans. As mentioned earlier, Taiwan is examined in a global context to provide insight into how masculine subjects interact with international politics and economics.

Three of key examples are provided in regard to how men practice and construct masculinities: aluba, doing soldier, and flower drinking. These three examples represent three life stages in which men develop their masculine selves (respectively, adolescence, early adulthood, and middle adulthood) and three social fields where masculinities are constructed (school, the military, and work). These processes are part of the common experience and collective memory of most Taiwanese men, and all three are sex-related.

We use mixed methods to explore diverse social fields. Aluba and doing-soldier studies mainly come from in-depth interviews and participatory observation respectively conducted by Bih and Huang (2012) and Kao (2006), supported by analysis on secondary data (e.g., newspapers, journals, photos, video, and online materials). The flower-drinking case is derived from secondary analysis of the studies by Hwang (2003), Bedford and Hwang (2011a, b), and Chen (2006).

We first describe the social settings of the three cases. The construction of masculinity and masculine selves in different contexts is then discussed, along with how the identity of Taiwanese men has changed through the process. Then, by comparison with Mac an Ghaill's (1994) Western pattern of masculinity, we discuss how the Taiwanese case shares some features of masculinity found in other societies but also shows discrepancies and explore the implications of these differences to our understanding of global masculine selves. Finally, empirical data are used to propose a concept of "masculinity in ambiguity" to shed light on those masculine selves who live on the periphery of the great powers and are characterized by either vague or unrecognized national identities. 


\section{Making Taiwanese Masculinities: Aluba, Doing Soldier, and Flower Drinking}

\section{Aluba}

Aluba is a popular activity on campus among adolescent male peers in which three or four boys lift up another boy by his arms and legs and pretend to attack him by rushing him crotch-first toward a flagpole or some other similar object. In the Western world, a similar activity can be seen in a scene in the film The Faculty in which it was presented in the context of bullying. However, in Taiwan, this activity took on a more complicated meaning and has been transformed into a game played for mutual amusement. The activity itself is now referred to as aluba and involves "alubers" staging a mock attack on the "alubaee," while the audience shouts encouragement to foster a cheerful atmosphere. The alubaee is not necessarily physically small or weak; nor is he seen as an object of bullying. In fact, the alubaee normally has a good relationship with his peers, and different boys in the group will take turns assuming the role of alubaee. Schools have banned the practice, but the ban is rarely enforced.

We propose the following conditions which support the popularity of aluba. (1) Credentialism is an important value for Taiwanese people, and students spend the vast majority of their time engaged in academic study. This leaves them a need to vent social and academic pressure. (2) That students sit in assigned seats in a specific classroom leads to the development of intense friendships within the class. Aluba allows these groups of boys to express their friendship through physical contact and shouting. (3) Adolescent boys are curious about sex. Aside from watching pornographic materials, only $20 \%$ have had sexual experience (Department of Health 2007). Aluba is a form of group interaction with distinct sexual overtones which allows the participants to establish their male identity. (4) Unlike team sports, aluba does not require a high level of skill, and the conditions required (e.g., access to a flagpole) are easily fulfilled. The above-mentioned characteristics make aluba a popular impromptu activity in Taiwan (Bih and Huang 2012).

\section{Doing Soldier}

After graduating from school, young Taiwanese men are institutionally directed to the next life stage. Doing soldier (chòe-peng in Taiwanese) represents a process in which Taiwanese men are theoretically transformed from boys into men and construct their masculinities through compulsory military service. All male citizens aged 18-35 are subject to 1-2 years of conscription, ostensibly to train them as skillful warriors who then serve as reserves upon release from active duty. This conscription system is a political and historical product, instituted by the KMT government (led by Chiang Kai-shek) after its relocation from China in 1949 following its defeat in the Chinese civil war. However, nearly 50 years of détente and thawing relations across the Taiwan Strait have gradually undermined the original 
legitimacy of the conscription system. Trainings are routinized, and daily operations are more of an exercise in fulfilling bureaucratic requirements than to train a real fighting force. Thus, the cultural gender meaning of military service has become more salient than its ostensible military purpose. The process of doing soldier can be observed at both structural and interpersonal levels.

Structurally, doing soldier represents the ways in which the state sought to establish a new pro-military masculine ideal type. After World War II, following the retreat of Taiwan's former Japanese colonial masters, the incoming KMT found the local population infused with anti-militarist sentiment. For example, proverbs such as "Good men won't serve as soldiers; good iron won't be used as nails" expressed a resistance to military institutions (Kao 2006). To counter these sentiments, the KMT launched an official propaganda campaign to establish military service as a necessary rite of passage for all men, using slogans such as "Heroes are those who hold weapons and protect the society." In addition, nursery rhymes and popular songs with militaristic themes were actively promoted to instill the idea that every boy desires to follow their male seniors to serve in the military. In this case, at the structural level, "doing soldier" implies the institutional and historical construction of nation-guaranteed masculinity.

At the interpersonal level, "doing soldier" captures the living daily practices of manhood and male bonds that facilitate to formulate contemporary Taiwanese masculine identities. Borrowing from the characteristics of "doing gender" (West and Zimmerman 1987), doing soldier "involves a combination of socially guided perceptual, interactional, and micropolitical activities that cast a particular pursuit as an expression of masculine ... "natures"' of the soldier's identification (p. 126). By formulating the process of conscription as doing soldier, we presume that being a soldier is not a given identity but a dynamic process in which men shed their "rookie" identity, earn recognition, and even compete for hegemonic status. For some, this experience includes losing their virginity to prostitutes in the company of members of their unit. Both openly gay and closeted soldiers may also have their first same-sex encounters at this time, regardless of whether their units are gay friendly or not.

In this case, practicing doing soldier trains teenagers to become adults and prepares them to pursue their future careers. The state has successfully established a guaranteed hegemonic and military masculinity, and inserts it to the life course of all Taiwanese men. Conscripts are equipped with work ethics and social networks, and inducted into the masculine culture through male bonding. In doing soldier, they are instructed about how to properly perform their gender and sexuality, which get them ready to step into workplace.

\section{Flower Drinking}

Flower drinking is a set of social practices in which a group of men visit commercial sex clubs (frequently under the guise of teahouses, karaoke bars, dance halls, nightclubs, barbershops, and so on) that offer a variety of erotic entertainment services (Hwang 2003; Simon 2003). 
In imperial China, education was largely restricted to men, who thus found it difficult to engage in intellectual discussion with their uneducated wives and often preferred the company of professional courtesans, trained in music, poetry, painting, and chess. During the Japanese occupation of Taiwan, upper-class men entertained guests at dinners accompanied by singsong girls, while laborers pursued sexual activities in brothels. Taiwan's sex industry continued to flourish and diversify with the KMT's arrival in 1949, with economic growth and social mobility feeding a large and diverse market for pornography and prostitution under various guises catering to men of different socioeconomic classes. Businessmen and government officials frequently sealed negotiations at entertainment venues under a set of practices euphemistically known as flower drinking (Simon 2003). These practices included group toasting, telling jokes, singing, raucous drinking games, and physical contact. Sexual gratification was not necessarily the point of these encounters, which served more as a group activity in which women served as social facilitators allowing the men to establish personal relationships, build networks, and accomplish business transactions (Hwang 2003).

\section{Development of Hegemonic Masculine Selves in Taiwan}

Prior studies on masculine culture have identified many key elements in establishing male bonds and masculine selves. Moreover, Taiwanese cases show some similarities and disparities from Western cases.

\section{Compulsory Heterosexuality, Misogyny, Homophobia}

Mac an Ghaill (1994) clarified three main cultural elements of the construction of subjects for heterosexual male students: (1) compulsory heterosexuality, (2) misogyny, and (3) homophobia. These elements are achieved through gender boundary maintenance, supervision, and justification of heterosexual male identification. Thus, the heterosexual male is involved with dual relationships: on the one hand, external relationships which are abusive to females and homosexuals and, on the other hand, internal relationships which remove femininity and homosexual desires. In a similar vein, Youdell (2005) believed that sex, gender, and sexuality have become an integrated whole in students' daily practices (including physical behavior, play, and clothing) to shape subjective identity. To establish dominant masculinities in schools, boys try to keep a distance from girls (Nardi 1992), endure risks (Seidler 2006), and gather together in gangs to exercise control over space (Whitehead 2002). Based on these findings, we discuss aluba, doing soldier, and flower drinking in terms of how Taiwanese men's sex, gender, and sexuality develop over the course of life.

Aluba represents a collective activity in which boys start to become accustomed to misogyny and heteronormativity early in school life. Basically, aluba is a malebonding game played exclusively by male peers without any female participants 
and explicitly rejects femininity. Adolescent boys find alubaing to be an appropriate way to celebrate a friend's birthday, whereas eating birthday cake is seen as being too feminine. Aluba not only excludes females and femininity but actively reassures the participants' internal male identity. The male identity in aluba is mainly organized around sexual symbols. For example, by showing (real or mock) pain, the alubaee certifies that he has a penis, which proves his biological maleness. As seen in a self-made documentary, ${ }^{3}$ school boys playing aluba creatively use campus equipment to demonstrate their sexual ability by supposedly damaging handrails and other objects or by turning on lights by ramming the light switch with the alubaee's crotch. Given the general inappropriateness of stripping down for visual inspections, the "products" of aluba (e.g., damaged rails) allow boys to symbolically verify their maleness, perform their sexual strength, and consolidate their solidarity. In addition, aluba is explicitly understood to not imply homosexuality on the part of participants because "being gay" (gao gay) would ruin their fun and pollute the purity of their heteronormative masculinity. But it isn't to say that closeted gay students would not pass as straight to join in aluba activities where male-on-male physical contact is legitimate. In the meantime, aluba opens a space for straight boys to enjoy pleasure from bodily intimacy among boys while not risking their hetero-normality (Kehily and Nayak 1997).

The misogyny, male bonding, and compulsory heterosexuality that male teenagers learn in school are further consolidated and developed when they transition to doing soldier. While women are now allowed to serve in the military, the ROC armed forces are still over $90 \%$ male. This intense proximity of men brings out a greater diversity of masculinities from the larger society. Men from different social classes, educational levels, regions, religions, languages, gender parameters, sexual orientations, and degrees of socialization live together in the military, and are forced to undergo a "secondary adjustment" to each other and the military institution (Goffman 1961). In such a highly masculine but diverse climate, men's cultural scripts, sexual games, and seniority (discussed later) are the three main gender lessons that conscripts learn from doing soldiers.

Cultural scripts are the gender lesson that Taiwanese men learn from doing soldier. To survive in the military, they have to understand a specific etiquette: To whom should they salute, as opposed to shaking hands? How should they properly show friendship with smiles and greetings? Material exchange is another issue. For example, "offering cigarettes" is one of the easiest ways to show friendship, to articulate a relationship, or to build up a male circle. Sometimes "serving wine" at round-table banquets has similar meanings, while it also creates the chance to test the relationship, explain misunderstandings, and reconcile conflicts. In addition, it is well known that bringing "concepts" (food as gifts) back to the barracks after off days is the accepted way to show concern for colleagues and respect to seniors. Here abstract concepts of seniority have been materialized as rituals of giving gifts of food to one's seniors or colleagues. This conceptualization of hierarchy ethics shows in the language used by conscripts, in which the food is referred to as a "concept," where the one with concepts (i.e., the one who brings the concepts back to the barracks) has concepts (of hierarchy, seniority, and solidarity). The distribution and exchange of cigarettes, drinks, and food represent the subtle infrastructure 
upon which male bonds are built and are important for establishing an "in group" among men. The roles of females in sexual fantasies and the at-risk masculinities shown in conscripts' sexual life and games further confirm misogyny, compulsory heterosexuality, and homophobia.

Generally speaking, the climate of panoptic surveillance and repressed sexual conduct in the military results in a deep castration anxiety for Taiwanese men (see Simon and Gagnon 1987's discussion on sexual conduct). Accounts on the intensive initiation training indicate a lack of sexual fantasies or arousal. A widely distributed rumor holds that vaccinations received on the first day of training include a "docility shot" and that additional "docility medicine" is added to their drinking water to intentionally suppress sexuality. One of Kao's (2006) interviewees reports that, on the last day of training, he happily announced, "I can finally be a man again today." Widespread rumors and fears of "secret medicines" to reduce conscripts' sexual impulse indicate how anxious the conscripts are and how dangerous they consider their masculinity to be as a result of coercive abstinence.

While sexual conduct is repressed in the military, sexual discourse is productive and widespread (Foucault 1990[1978]). Sexual jokes are ubiquitous. Some soldiers personalize and feminize their guns as "girlfriends," while others eroticize routine artillery maintenance activity as "jerking off the giant." Some soldiers may greet with each other by asking about or sharing details about their off-duty sexual encounters, while others engage in casual misogyny by complaining about female figures or using abstract female images in cursing (e.g., "Fuck yo muther" [kàn lí niâ]). The sexual rhetoric is not only personal but also institutional. In his ethnography, Kao (2006) observes that a warning sign on a refrigerator says, "It is not easy to purchase and maintain the machine. Please treasure it as much as you do your girlfriend" (p. 154). Given the low proportion of female soldiers and officers, women are physically absent in most military situations but are symbolically ubiquitous through these types of sexualized discourse and misogyny.

Nonheterosexuality in the military complicates sexual scripts among soldiers (Simon and Gagnon 1987). Taiwan has no equivalent of a "don't ask, don't tell" policy to prevent homosexuals from serving, but a pervasive climate of homophobia exists at the interpersonal level, with constant jokes about "picking up soap" implying anal sex among men. Any actions perceived as feminine can label a recruit as suspiciously unmasculine and single him out for ridicule. On the other hand, gay conscripts may queer the heteronormative environment through their fantasies. Some gay interviewees in Kao's (2006) in-depth interviews indicated that they queerly reread the heterosexualized routine scenes of artillery maintenance. They recognize that their straight colleagues are engaged in imagined masturbation by feminizing the weapon; however, rather than feel uncomfortable by being marginalized, these gay conscripts enjoy watching the scenes of physical exertion as if their straight colleagues were really masturbating. Traditional conditions of sexual harassment are also queerly reread and practiced. One interviewee reported playing a semi-sexual harassment game with his superiors in which his superiors chased and held him while he was supposed to avoid capture. Though he indicated no interests in these "old, ugly, fat" superior officers, he did enjoy playing 
the sexual game because it was fun and helped him establish a better relationship with his superiors. As Kao notes:

Sexual games are the lubricant in rigid bureaucratic relations... Via sex and sexual games, men collage and reorganize their fragmented selves, which have been deconstructed and destroyed by military governance. The sexual symbols that men use in sexual languages and games refer not only to physical genital sex. They are also derived from local military equipment and shared experience, which are consciously and creatively appropriated and transformed into collective fantasies. This mechanism facilitates the accomplishment of a collective eroticism and masculine identity in the Taiwanese military. (Kao 2006, p. 156)

The development of masculine selves is related to how men interact with female actors in a given context. In terms of flower drinking, Hwang (2003) indicated that sexual club hostesses play three kinds of roles: (1) Caretakers who attend to and pacify the male participants while showing obedience and playing the role of gentle and uncritical listener. (2) Social facilitators, initiating and maintaining a cheerful atmosphere to help their male customers to please their clients. Facilitated by the hostesses' services, men can shed their public personas, thus eliminating defensive and social distance. (3) Sexual objects, flirting and playing sexual games with male customers. In other words, the hostesses play both sexy sluts and docile maids at the same time to foster men's male bonding and their masculinity.

It is noteworthy that even if flower drinking is highly sexual, the main purpose of flower drinking is not sexual intercourse. If men want sex, brothels present a more convenient and less expensive option than flower drinking. Rather, the point of flower drinking is to have a good time and bond with other men (Bedford and Hwang 2011b, p. 89). Through the attention of compliant women, flower drinking gives men a sense of power and raises their self-image. The attention of the hostesses is seen as a gift from the male host to his guests, as opposed to a monetary bribe. Managers use it to promote group bonding; businessmen use it to close deals and have a good time. Through the uncritical attention of the hostesses, men "become emperors," and the hostess club is "like a gas station where the hostesses could refill [the client's] masculinity" (Bedford and Hwang 2011b, p. 90).

Flower drinking has become an institutionalized practice and is an important aspect of career performance for men. Rather than admit to sexual desire, men rather regard flower drinking as a normal type of social engagement or just "go along for the ride" to fit in the culture without guilt. Thus, flower drinking allows for the completion of business transactions but also fulfills the clients' erotic desire.

\section{Quanxi}

The discussion above explains why Taiwanese masculinities share similar characteristics of misogyny, homophobia, and compulsory heterosexuality raised by Mac an Ghaill (1994) to construct heterosexual male subjects. In addition to the three global elements, in the local context "guanxi" (social networking) and male bonding are critical in the construction of Taiwanese masculinity. 
In aluba, the focus is the alubaee. Seemingly, the alubaee's body is controlled by the alubaers, but in fact, he is simultaneously treated as an object of worship. As one interviewee noted, "I don't think [being alubaed] entails a loss of male dignity. Instead, they have built a stage for me and allowed me to be the centre of public attention" (Bih and Huang 2012, p. 155). The person who is most frequently alubaed is usually characterized as being companionable, amenable, and loyal, while showing leadership qualities. Mutuality is thus very important in that role switching is an integral part of the activity. While relationships among adolescent boys are quite simple and pure, military conscripts have to build good gaunxi to pursue one's own interest in a very harsh environment. And, as students move from school to the military, their formerly equal status gives way to a formal hierarchy among soldiers.

In contrast to official military ranks, seniority is a type of informal but powerful gaunxi. In the Taiwanese military, seniority is based on hidden transcripts that create hierarchies among conscripts by the time they enter the military. Chen (2004) characterized it as an "order of time," in which "soldiers are divided into two groups - senior and junior. Soldiers perform differently according to how they are located in different stages of the senior-junior status: the junior's body always shows a kind of 'voluntarily energetic manner,' while the senior acts 'sluggishly", (p. 181). Compared with their status in civil society where men may be born into middle or upper positions of gender, class, and racial/ethnic hierarchies, in the military every man starts out by being degraded, stripped of any previously taken-forgranted privileges. Conscripts have to climb the ladder of seniority, from "nonhuman" through feminized human ("pussy," "lady"), manhood, and finally alpha male.

Unlike in ordinary workplaces and organizations, seniority in the Taiwanese military is characterized by two unique aspects. Firstly, new recruits rise up the seniority escalator very rapidly, with men being promoted from the extreme bottom to the top in just 1 or 2 years, as opposed to decades in conventional organizations. Secondly, seniority is interwoven with the official ranking system to create a unique but paradoxical "dominated male-dominator" culture. On the one hand, those at the top enjoy privilege and respect from their juniors, but they are well aware that they are still subordinate to others who outrank them. On the other hand, higher-ranked officers may also have to show respect and share power with those who have lower official rank but rank higher in terms of seniority. This interweaving of seniority and rank provides an environment in which Taiwanese men learn to execute power over the powerless, obey the powerful, and maneuver within the gap between the two. In this case, Taiwanese conscripts show us that men are not born to be dominating but learn to dominate some and be subservient to others, as circumstances dictate.

In commercial workplaces, in addition to swapping stories from their time in the military, men participate in flower drinking as an important means to build guanxi, extend social networks, and achieve work-related goals. In these activities, men exchange political and economic interests in a fun and convivial atmosphere. Flower drinking is institutionalized as a social game. Frequent customers bring personal desire to the game of power exchange in the public sphere under the guise of official affairs or work. In addition, many are in a position to use nonpersonal funds (either corporate or government) to engage in flower drinking, and the ability to host such activities grants men a higher status among their peers. A man who refuses to join in might be ridiculed 
and criticized for not showing respect for others and lacking machismo (Bedford and Hwang 2011a). Men's masculine identities are also reinforced in these processes.

\section{The Developmental Perspective of Masculinity}

Here, we address a more comprehensive framework of masculinity which considers the global roles of sex, gender, and sexuality, as well as local elements of guanxi, and takes into account the developmental perspective, such as the evidence provided by aluba, doing soldier, and flower drinking.

The roles of sex, gender, and sexuality become prominent as early as adolescence. Although fewer than $20 \%$ of adolescent boys in Taiwan report having engaged in sexual intercourse, their participation in aluba provides way to explore sexuality. By symbolically attacking the genitals of their male peers, boys confirm their male identity and bonding. Girls are entirely excluded from aluba, but the activity does not seek to devalue or depreciate girls.

For Taiwanese men in their early adulthood, mandatory military service constitutes a national rite of passage. During the service, even if most male conscripts are physically separated from women in single sex dormitories, women are symbolically present through jokes and banter during training. In addition, during this life stage, some conscripts have their first exposure to the commercial sex work industry. Sexual games learned from school, like aluba, are also integrated into military life and are extended through other forms of roughhousing and competitive drinking. Thus, while seniority and cultural scripts constitute the institutional and interpersonal guidelines of the masculine community, sexual games provide the intrapsychic links that sociopsychologically enclose men into one collective masculine identity: we are we-man, not women (physically or symbolically).

As men grow older, sex moves from the area of imagination to that of actual practice. Aside from sex with intimate partners, some men buy sex in brothels. Flower drinking, meanwhile, functions as a way to build male bonding and fulfill job goals, with women (hostesses) serving as mediators to create and maintain a festive atmosphere, facilitate male bonding, and flirt with male customers. To strengthen male dominance, male customers release their repressed emotion and desire through buying the hostesses' services. In addition, since working women or businesswomen cannot participate in flower drinking, they are deprived of the opportunity to exchange information or build useful relationships (Hwang 2003) and thus suffer from reduced competitiveness in the job market. Women in marriage are also hurt because of their husband's engagement with other women.

\section{Conclusion: Masculinity in Ambiguity}

This research provides with a life-span study of Taiwanese masculinities to compensate for the incomplete understanding of East Asian masculinities in the Englishspeaking world. We argue that the previous neglect of Taiwanese masculinities is 
not accidental but a result of the structured framework of international politicoeconomics, which is represented in the daily practices of Taiwanese men. Taiwan's vague diplomatic status produces a structural setting for what we call masculinity in ambiguity, a unique configuration of masculine practices that we observe in Taiwanese men's self-development. Masculinity in ambiguity is manifest in four dimensions: international, institutional, interpersonal, and developmental.

In the international dimension, Taiwanese men have been constituted as inherently dependent. Following World War II, international powers (especially the USA) treated Taiwan as a buffer between the democratic world and the communist world. After the ROC was replaced by the People's Republic of China as China's sole representative in the United Nations in 1971, Taiwan subsequently lost diplomatic relationships with most countries, becoming an unrecognized entity and buffer among mega-powers (e.g., the USA, Japan, and China). Since then, Taiwanese men have existed in an ambiguous state, as citizens of a country that is not widely recognized but whose passports are widely accepted, an energetic and influential economic entity that is excluded from most international organizations. Thus, on the international stage, suppression by China and exclusion by other countries force Taiwanese men to learn to survive in a highly constricted diplomatic space. Their survival has multiple meanings: it identifies men as the default breadwinners (economic strength) and assigns them the role of securing Taiwan's position from being undermined by China (political strength); it shows how eagerly men desire pride ("the Glory of Taiwan") but how fearful they are of displaying it; in addition, their survival indicates how Taiwanese men struggle with double castration anxiety, which implies racial castration as stereotyped feminine men and national castration as unrecognized global citizens. Hence, the international structure fragments and restricts Taiwanese masculinities, creating ambiguity at the next, institutional level.

At the institutional level, masculinity in ambiguity represents the various interactions between the top, hegemonic masculinity, and the bottom, subordinate masculinity (Connell 1995, 2005). Its in-between position has resulted in it being ignored by previous studies, which usually focus on the polarized extremes. As we have shown, three popular men's activities_aluba, doing soldier, and flower drinkingcapture the practices of men positioned in the middle of gender, class, and body hierarchies, while the situated hegemonic and subordinate men are left out of the scope. At school, shy, self-contained, and academically oriented students (nerds) resist participating in the pseudo-violent activities of aluba, while truly rebellious students disdain aluba as being too feminine and childish. Despite its obligatory nature, doing soldier also demonstrates the privileges of elites who can use their social connections to secure a waiver, while the physically and mentally unfit are also excluded from military service. In addition, as a popular heterosexual activity for middle- and upper-ranking businessmen, flower drinking excludes the working class, the unemployed, women, and homosexuals. Positioned at the top of the economic hierarchy, the elite can exploit their economic and political power without partaking in flower drinking. The ambiguity shown in the institutional dimension demonstrates the participants' standing in the middle of the class, gender, and sexuality hierarchies. They are neither powerful nor powerless but somewhere in the 
middle. To achieve career and social success, these "middlemen" have to develop many survival strategies to develop and secure their selves at the interpersonal level.

The ambiguity during men's interpersonal interaction emphasizes how vague, multifold, and flexible these masculine practices are in exercise and interpretation. The hidden dramaturgical scripts in different situations are widely recognized but unmentionable (Goffman 1959). In aluba, men seem to attack the other's genitals, but there is no actual injury or humiliation. Rather, it's seen by all participants as simply a way to celebrate a birthday, show friendship, share happiness, or just have fun. Hurt feelings, sexual arousal, or actual injury would ruin the fun. During doing soldier, the dramaturgy is even shared in the collective identity. People say, "In doing soldier, nothing is real except demobilization" (Kao 2006). Soldiers consciously understand they are involved in a great drama and make fun of the roles they are expected to play. A commanding officer is seen as the director, while the subordinates are actors. However, the "directors" in this scenario are also subordinate to others, and each actor may have superiority over actors whom he can direct as he sees fit, thus preserving his "face" (dignity). In addition, some digital-generation conscripts conceptualize their military selves as virtual, like identities created in online games. In this line of thinking, being on duty is the equivalent of logging on, while being off duty allows one to retreat into civilian life. In this case, the differentiation between old selves and role-playing, between offline and online, creates a necessarily ambiguous zone. In this ambiguous state, it is acceptable for masculine men to be totally obedient to other men (because it is just a drama); otherwise, disreputable conduct experience in the military does not violate their own civilian self-identities (because it is a virtual existence). Ambiguity at the interpersonal level also explains why men can have sexual fun with unfamiliar girls in flower drinking without ruining their self-image despite their wives, mothers, and daughters waiting for them at home. For them, flower drinking is considered as just the way to "join in the fun on occasion" and is not to be taken seriously. Thus, flower drinking creates another ambiguous zone between the workplace and home-an inbetween place where those who dislike the culture can justify their involvement by saying it is just for business - thus allowing them to maintain a companionate intimate relationship in marriage. For those who intend to enjoy the experience, the ambiguity provides a legitimate reason to do it as a group. Therefore, ambiguity at the interpersonal level provides a gray area for men to suspend their conventional identities, insulating their dignity from feelings of guilt, shame, or responsibility. Because masculine selves in ambiguity are temporal, occasional, and flexible, men feel comfortable crossing boundaries of same-sex touching (e.g., in aluba), to be degraded as powerless and gradually assume power (doing soldier) and to strategically use sexual services to exchange economic interests without self-condemnation.

Lastly, this study depicts the final level of masculinity in ambiguity, the developmental level. These masculine selves have been developed in an ambiguous situation from adolescence through early adulthood to mid-adulthood. As we have seen above, Taiwanese men start to play multi-meaning games in school. They are then separated from nurturing females and forced into close ties with their male peers and senior men to learn men's culture, inherit the state's consolidated patriarchal ideology, and establish male bonding for future use. After demobilization, men return to society to be reunited with their families as nominally independent adults, expected to fit in established 
masculine categories. Throughout this process, men gradually become accustomed to performing their required scripts, have fun during the performance, and eventually become socialized as certificated masculine beings. In this process they may have opportunities to deviate from the script or resist each instituted design. But these resistances rarely challenge the construction of ambiguous masculinities in their life courses.

To conclude, the concept of masculinity in ambiguity provides a new framework of sociopsychological masculinity studies in the era of globalization. We argue that national boundaries and identities should not be considered as default categories of state-based masculinity. Taiwan lacks recognition as a country but shows great diversity and theoretical potential of masculinity. In a globalized context, local masculine selves are penetrated and infiltrated by transnational power. We expect that future men and masculinity studies take account of the four levels of ambiguity-international, institutional, interpersonal, and developmental — to assess how these vague, multifold, and flexible forces operate and are interwoven to constitute globalized masculine selves.

\section{Notes}

1. Taiwan's international economic influence is not correspondingly reflected in its diplomatic significance. As of 2009, Taiwan has the world's fourth largest foreign currency reserves and was the world's 26th largest economy (Global Trends 2009). Taiwan's high-quality labor force and high literacy rates have helped it emerge as a world-class supplier of high-technology products (electronics, semiconductors, and digital displays). Other achievements include Taiwan's development as a leader in the greater China cultural and creative industries, while providing Taiwan's citizens with equitable access to advanced health-care services. This huge structural gap between Taiwan's position in international politics and the global economy is the basis of the main institutional contradiction which profoundly influences Taiwanese masculinity.

2. The "yin-yang" dyad provides a metaphysical view which splits the universe into dichotomies. In human society, yin-yang corresponds to binary sex (female-male) and gender (femininemasculine). In nature, people also use yin-yang to dichotomously acknowledge the world (dark-light, moon-sun, water-fire, life-death, and so on). Although it grants the possibility for the mutual interaction and reciprocal change of two poles, the yin-yang philosophy produces a tautological fallacy, which tends to use societal order to explain natural law, which is then used to perpetuate societal order.

3. Hrcspkla. (2006). 313 aluba rite of passage. Retrieved Jan 12, 2010 from http://www.youtube. $\mathrm{com} /$ watch?feature=player_detailpage $\& \mathrm{v}=\mathrm{yqN} 41 \mathrm{TgChFU}$

\section{References}

Bedford, O., \& Hwang, S.-L. (2011a). Building relationships for business in Taiwanese hostess clubs: The psychological and social processes of guanxi development. Gender, Work and Organization. doi:10.1111/j.1468-0432.2011.00576.x.

Bedford, O., \& Hwang, S.-L. (2011b). Flower drinking and masculinity in Taiwan. Journal of Sex Research, 48(1), 82-92.

Bih, H.-D., \& Huang, H. (2012). Aluba and "high" culture: Adolescent male peer culture in play. Gender and Education, 24(2), 147-158.

Chen, C.-L. (2004). Engendering soldiers in the Taiwanese military: Obedience, masculinities and resistance. Unpublished doctoral dissertation, Lancaster University, Lancaster. 
Chen, M. H. (2006). Labour, the body, and sexuality: Women sex workers' negotiation of public and private sex and work. Taiwanese Sociology, 11, 1-55 (in Chinese).

Connell, R. W. (1987). Gender and power: Society, the person and sexual politics. Stanford: Stanford University Press.

Connell, R. W. (1995). Masculinities. Cambridge, UK: Polity Press.

Connell, R. W. (2002a). Gender (polity short introductions). Malden: Blackwell.

Connell, R. W. (2002b). Study men and masculinities. Resources for Feminist Research, 29(1-2), 43-56.

Connell, R. W. (2005). Hegemonic masculinity: Rethinking the concept. Gender and Society, 19(6), 829-859.

Department of Health (2007). Global student reproductive health survey. Retrieved Oct 24, 2012 from http://www.doh.gov.tw

Doyle, J. A. (1989). The male experience (2nd ed.). Dubuque: Brown.

Foucault, M. (1990[1978]). History of sexuality: An introduction (Vol. 1). New York: Vintage Books.

Global Trends (2009). Corporate clout: The influence of the world's largest 100 economic entities. Retrieved Aug 24, 2012, from http://www.globaltrends.com/knowledge-center/features/ shapers-and-influencers/66-corporate-clout-the-influence-of-the-worlds-largest-100economic-entities

Goffman, E. (1959). The presentation of self in everyday life. Garden City: Doubleday.

Goffman, E. (1961). Asylums: Essays on the social situation of mental patients and other inmates. Garden City: Anchor Books.

Hwang, S. L. (2003). Masculinity and Taiwan's flower-drinking culture. Taiwanese Sociology, 5, 73-132 (in Chinese).

Kao, Y.-C. (2006). Doing soldier as a male ritual: A study of the service process of conscripted soldiers' masculinities in Taiwan (2000-2006). Master's thesis, National Taiwan University, Taipei City. (in Chinese).

Kehily, M. J., \& Nayak, A. (1997). 'Lads and laughter': Humor and the production of heterosexual hierarchies. Gender and Education, 9(1), 69-87.

Kimmel, M. S., Hearn, J., \& Connell, R. W. (Eds.). (2005). Handbook of studies on men and masculinities. Thousand Oaks: Sage.

Louie, K. (2002). Theorising Chinese masculinity: Society and gender in China. New York: Cambridge University Press.

Louie, K. (2003). Chinese, Japanese and global masculine identities. In K. Louie \& M. Low (Eds.), Asian masculinities (pp. 1-15). London: Routledge.

Louie, K. (2007). Chinese masculinities. In M. Flood, J. K. Gardiner, B. Pease, \& K. Pringle (Eds.), International encyclopedia of men and masculinities (pp. 63-65). London: Routledge.

Mac an Ghaill, M. (1994). The making of men: Masculinities, sexualities and schooling. Philadelphia: Open University Press.

Nardi, P. M. (1992). Seamless souls: An introduction to men's friendship. In P. M. Nardi (Ed.), Men's friendships (pp. 1-14). Newbury Park: Sage.

Said, E. W. (1978). Orientalism. New York: Vintage Books.

Seidler, V. J. (2006). Young men and masculinities: Global cultures and intimate lives. London: Zed Books.

Simon, S. (2003). Sweet and sour: Life-worlds of Taipei women entrepreneurs. Lanham: Rowman and Littlefield.

Simon, W., \& Gagnon, J. H. (1987). A sexual scripts approach. In J. Geer \& W. O’Donaghue (Eds.), Theories of human sexuality (pp. 363-383). New York: Plenum.

Simon, W., \& Gagnon, J. H. (2003). Sexual scripts: Origins, influences and changes. Qualitative Sociology, 26(4), 491-497.

Taga, F. (2005). East Asian masculinities. In M. S. Kimmel, J. Hearn, \& R. W. Connell (Eds.), Handbook of studies on men and masculinities (pp. 129-140). Thousand Oaks: Sage.

West, C., \& Zimmerman, D. H. (1987). Doing gender. Gender and Society, 1(2), 125-151.

Whitehead, S. M. (2002). Men and masculinities. Cambridge, UK: Polity.

Youdell, D. (2005). Sex-gender-sexuality: How sex, gender and sexuality constellations are constituted in secondary schools. Gender and Education, 17(3), 249-270.

Zhong, X. (2000). Masculinity besieged? Issues of modern and male subjectivity in Chinese literature of the late twentieth century literature. Durham: Duke University Press. 